\title{
Shaping a Participatory Health Communication Pedagogy with UX and Patient-Agency
}

\author{
Danielle DeVasto \& Lori Beth De Hertogh
}

"But the most important and far-reaching experiences we participate in almost every day of our professional lives is architecting our students' classroom experiences and the environments in which they learn to become professionals" (Potts \& Salvo, 2017, p. 6)

\section{Introduction}

A primary goal of health and medicine is enacting patient-centered care, or the practice of making patient needs and desires the "centerpiece" of medical care (Berry et al., 2014). We see patient-centered care happening all around us - a nurse who takes extra time to listen to a patient with diabetes; a provider who offers an elderly cancer patient not just one treatment option, but several; a physician who works across areas of specialty to understand a patient as a "whole person.” In essence, patient-centered care is just what it sounds like—it's about seeing patients as people and not just as bodies that need repair.

The tenets of patient-centered care are surprisingly similar to an area of study many rhetoric of health and medicine (RHM) teacher-scholars are familiar with-user experience. Broadly defined, user experience "focuses on having a deep understanding of users, what they need, what they value, their abilities, and also their limitations" (Usability.gov, n.d.). Like patient-centered care, user-experience (or UX) is about putting people at the center of an experience. It's about designing things like apps, buildings, vehicles, and websites so that anyone, no matter their background or ability, has their needs met. More than usability or 
accessibility alone, UX is the whole package — it's about understanding and responding to all of a user's abilities and needs.

As RHM teacher-scholars, we see patient-centered care and UX as complementary frameworks that can meaningfully inform teaching approaches in RHM. Our goal, then, in this short article is to conceptualize and share a framework we call a participatory health communication pedagogy. This approach merges UX and patient-centered concepts and practices in order to put students at the center of their classroom learning experiences. While UX and patient-centered care are often topics taught about, we suggest that these frameworks can be actively used in our classrooms by positioning students as both content creators and as content users. As we illustrate throughout, a participatory health communication pedagogy enhances student learning by:

- Centering students as active learners/users who shape their classroom experiences (e.g., course structure, materials, assessment)

- Maintaining a concern for usefulness as defined by the goals and measures of students as well as the instructor, department, or university

- Soliciting input through consistent feedback loops or checkpoints

A participatory health communication pedagogy can be used in any writing studies class, but is especially applicable to RHM courses ${ }^{1}$ that already emphasize patient-centered care. For RHM students, we see a particular advantage — a UX-informed pedagogy models the kind of user-

\footnotetext{
${ }^{1}$ We use the phrase "RHM courses" while acknowledging that the focus and naming conventions of courses in RHM are varied. As Daniel Kenzie and Mary McCall (2018) point out, RHM courses often fall under various titles such as disability studies, healthcare writing, medical humanities, and science writing. Jennifer Malkowski, J. Blake Scott, and Lisa Keränen (2016) note the variability of naming conventions in RHM more broadly, observing that "other names that might encapsulate rhetorical approaches to health and medicine include 'medical rhetoric,' 'discourse studies of health and medicine,' 'health rhetoric,' 'rhetorical health communication,' and 'rhetorics of health and healing' (p. 3).
} 
centered approaches that can be transferred to students' own professional contexts and approaches to doing patient-centered work. Both within the classroom and as students move beyond it, a participatory health communication pedagogy is an approach that aligns with calls for more socially just pedagogies because it encourages more inclusive and equitable practices that support and respond to a range of users, regardless of their age, gender, race, or ability. As the editors to this special issue point out, such approaches are essential for RHM teacher-scholars to meaningfully address "racism and interlocking systems of oppression" within our teaching and scholarship (Scott, Meloncon, \& Molloy, 2020).

\section{Brief Literature Review}

Over the last decade, scholars have increasingly considered ways that UX-informed pedagogies can enhance student learning. This is largely because educators have realized that UX principles and practices improve student learning not only in usability courses, but in any course that values diverse and inclusive learning approaches. One such example of the shift toward UX as a pedagogy is Kate Crane and Kelli Cargile Cook's (2022) work on UX as a pedagogical practice. They argue that UX "works beyond a course topic" as a concept that can better engage students and strengthen their learning experiences. In a similar vein, Natasha Jones (2018) in her article, "Human Centered Syllabus Design: Positioning Our Students As Expert End-Users," suggests that first-year writing courses can benefit from adopting a human-centered design approach where students are seen as expert end-users of core pedagogical documents like course syllabi. Similarly, in her collaborative article on user-centered design in the classroom, Ann Shivers-McNair et al. (2018) suggests that writing teachers might further consider the benefits of creating courses that are "designed not only to teach [...] usability testing, but also to be tested for usability" (p. 37). What these scholars illustrate is that there is value in applying 
(and not just teaching) user-centered approaches in a range of classroom contexts. In other words, there is intrinsic value in seeing the classroom as not just a space for teaching UX, but for enacting it as a pedagogical practice.

We propose that RHM educators are especially well-positioned to apply UX principles to student learning because these courses already often emphasize (either explicitly or implicitly) patient-centered care - a healthcare approach that puts patient needs and preferences at the center of healthcare practices. Like a user-experience approach, a patient-centered care model views the patient not simply as the recipient of a particular experience, product, or treatment but as an empowered agent whose needs and desires are actively responded to. Lisa Melonçon (2017) takes up this line of thinking in her work on "patient experience design" where she argues that technical communicators and healthcare providers must create content that prioritizes and centralizes user/patient needs. Thus, like both patient experience design and user-experience design models, a patient-centered care approach strives to create patient agency—or the process by which patients have the "language, respect, and information necessary" to make informed decisions about their health (Stone, 1997, p. 213).

A number of RHM scholars have examined how patients within healthcare systems create and enact patient agency. Lora Arduser (2017) illustrates how patients with diabetes establish their ethos as "expert patients" who are able to evaluate and manage their own health. In her work on Lyme disease and the “empowerment paradox," Sarah Singer (2019) further unpacks how we understand patient agency, arguing that while patients with Lyme disease are empowered by health information sharing platforms, they are simultaneously disempowered by the corporations who collect users' health data. Kim Hensley Owens (2015) offers yet another view of patient agency, arguing that pregnant people strategically use written birth plans to 
rhetorically influence their childbirth experiences in medical settings. In short, conceptions and definitions of patient-agency are complex and varied, but they all underscore that patients should have direct and ongoing influence over their own health.

Like patients in healthcare contexts, students can benefit from classroom practices that centralize their experiences as both learners and users. Doing so creates effective feedback loops between teacher and student and helps "address issues of power and agency" within classroom contexts by decentralizing the teacher's role and prioritizing student needs, values, and voices (Jones, 2018, p. 343). This said, it's important to acknowledge that student agency is different from patient agency. Classroom settings focus on student learning, while treatment settings emphasize patient well-being; moreover, students collaborate with their instructors in ways that express power dynamics differently than how patients work with their healthcare providers.

Despite such differences, the combined concepts of user-experience and patient-agency can serve as a useful framework to guide pedagogical practices in RHM courses. As we demonstrate in the following section, a participatory health communication pedagogy merges the values of patientagency with UX by encouraging students to make informed and ongoing decisions about their classroom learning.

\section{Applying a Participatory Health Communication Pedagogy}

In this section, we describe the central qualities or characteristics of a participatory health communication pedagogy. The table below provides a preview of what these features look like in the classroom and how they connect to UX and patient-agency practices. The case studies that follow provide a more in-depth look at how these qualities play out in RHM classrooms.

Table 1: Qualities of a participatory health communication pedagogy aligned with UX and patient-agency principles 


\begin{tabular}{|c|c|c|}
\hline Quality & $\begin{array}{l}\text { UX \& Patient-Agency } \\
\text { Principles }\end{array}$ & Classroom Example \\
\hline $\begin{array}{l}\text { Quality 1: Centers students } \\
\text { as active learners and users } \\
\text { who shape their classroom } \\
\text { experiences (e.g., course } \\
\text { structure, materials, } \\
\text { assessment) }\end{array}$ & $\begin{array}{l}\text { User-centered; aims to meet the } \\
\text { user/patient needs and take } \\
\text { user's context into consideration } \\
\text { Design for usability (i.e., easy to } \\
\text { use) and accessibility }\end{array}$ & $\begin{array}{l}\text { Student input on assessment } \\
\text { (e.g., justification memo; } \\
\text { students self-assigning } \\
\text { grades) } \\
\text { Student-generated documents } \\
\text { (e.g., task schedules and team } \\
\text { charters) }\end{array}$ \\
\hline $\begin{array}{l}\text { Quality 2: Maintains a } \\
\text { concern for usefulness as } \\
\text { defined by the goals and } \\
\text { measures of students as } \\
\text { well as the instructor, } \\
\text { department, or university }\end{array}$ & $\begin{array}{l}\text { Going beyond conventional } \\
\text { functionality; "usefulness" } \\
\text { (Mirel, 2004) } \\
\text { Interactive users }\end{array}$ & $\begin{array}{l}\text { Professional skills and } \\
\text { training (e.g., collaboration, } \\
\text { practicing PPC) } \\
\text { Students create real-world } \\
\text { deliverables that respond to } \\
\text { professional contexts }\end{array}$ \\
\hline $\begin{array}{l}\text { Quality 3: Solicits input } \\
\text { through consistent } \\
\text { feedback loops or } \\
\text { checkpoints }\end{array}$ & $\begin{array}{l}\text { User/patient is not just a } \\
\text { recipient but has valuable } \\
\text { expertise } \\
\text { Design as recursive }\end{array}$ & $\begin{array}{l}\text { Embedded checkpoints } \\
\text { Students help guide } \\
\text { classroom-decision making } \\
\text { around class projects, } \\
\text { guidelines, and materials } \\
\text { documents }\end{array}$ \\
\hline
\end{tabular}

To illustrate what this pedagogical approach looks like in practice, we then turn to two RHM classroom case studies. The case studies that follow illustrate the qualities of a participatory health communication pedagogy outlined in the above table. But before we describe how we embedded these qualities in our classrooms, we think it useful to first provide readers with background information about these two courses and how they are situated within broader writing studies curricula. 
Our first case study is a 400-level elective, "Scientific and Medical Communication," taught by Lori Beth De Hertogh in the spring of 2019 at James Madison University (JMU) in the School of Writing, Rhetoric and Technical Communication (WRTC). Satisfying credit hours for WRTC's technical communication concentration as well as the university's interdisciplinary Medical Humanities minor, this iteration of the course was developed around the theme of community health advocacy, with a focus on how patients with Type 2 Diabetes living in the Shenandoah Valley of Virginia perceive and manage their condition. Students participated in a community engagement project that brought together local healthcare professionals, community members, and $\mathrm{X}$ faculty.

Our other case study is a 200-level course on "Health Science Writing” taught by Dani DeVasto in the 2018-2019 academic year. While open to majors as an elective, this course primarily enrolls non-majors, and it satisfies a university requirement for oral and written communication credit. The course combines a series of speaking and writing assignments that introduce students to theories, practices, and ethics of health communication. For their final project, students collaboratively analyzed campus communication about a specific health issue (e.g., vaping, anxiety, STIs). Then, in conjunction with faculty and staff from across campus units, they developed artifacts to engage University of Wisconsin-Milwaukee students (e.g., podcasts, redesigned webpages, social media campaigns, infographics).

\section{Quality 1: Center Students as Active Learners and Users}

Merging the values of patient-agency with UX, a participatory health communication pedagogy encourages students to make informed and ongoing decisions about their classroom learning. Students are centered as active learners and users who shape their classroom experiences (e.g., course structure, materials, assessment). Making student experiences the focal point of classroom learning creates a pedagogical opportunity to center marginalized or overlooked users. 
De Hertogh's "Scientific and Medical Communication" course centered students as active learners and users through Teaching Analysis Polls (or TAPs), an informal mid-semester course evaluation designed by JMU's Center for Faculty Innovation (James Madison University). TAPs are designed to provide "instructors with rich qualitative feedback from their students regarding the learning environment in a course" and to "meaningfully include students" in the direction and design of a course. After a TAP session is requested, a faculty consultant works with students in small groups to help them self-evaluate their learning and identify changes they would like to see in the course. The faculty consultant later meets with the instructor to share the TAP results and brainstorm about how to use student feedback to enhance classroom learning.

In the context of this particular course, the TAP session played a critical role in helping De Hertogh collect data about students' perception of the purpose, function, and usefulness of the course, feedback that was used to revise class activities in real-time in order to center students as learners and users. For example, many students admitted during the TAP session that they were uncomfortable self-assigning grades, which they had been encouraged to do for the first course project. To better address student anxiety over self-assigned grades, De Hertogh devoted additional class time to discussing the pedagogical rationale for this choice and how this fit into the overall class goal to decentralize her influence and to work with students as true collaborators and learners.

In DeVasto's "Health Science Writing" course, one way students were centralized as active learners was by drafting several working documents to manage and evaluate their work. In organizational documents, like team charters and task schedules, students accounted for their motivations, needs, strengths, and limitations, allowing them to foreground their diverse 
experiences and contexts. For example, they noted special skill sets, like experience with building websites, desire to learn a particular software, community contacts, known tendencies toward procrastination, heavy work days, and family commitments. These experiences and preferences, then, shaped their group decisions, such as the resources they might use to complete the assignment, the roles each person might play, or when or how they would meet and work. These student-generated documents also informed the resources or class activities DeVasto prepared. Each group in the course also submitted a justification memo alongside their final project, which identified the rhetorical situation they were responding to, provided commentary on their design processes, and justified their choices. Through these memos, students contextualized their work and shaped how their final projects would be assessed.

\section{Quality 2: Maintain a Concern for Usefulness}

Mirel (2004) defines usefulness as "the ability to do better work, not just to use an application more easily" (p. xxxi). Applied to a classroom, this means going beyond making the course itself functional or usable (e.g., clear and consistent lines of communication, conveying information in multiple formats, and providing different means for engagement). It means designing a course that supports real inquiry, productive work, community-making, and "get-your-hands-dirty epistemic action" as defined by the goals and measures of students as well as the instructor, department, or university (Simmons and Zoetewey, 2012). By maintaining a focus on usefulness in concert with conventional usability, a participatory health communication pedagogy grants students power and influence from the outset.

Many of the students enrolled in De Hertogh's course were juniors and seniors who would soon enter the workforce as writing and technical communication specialists. To ensure that the course was both useful and usable, she organized the final course project (an online health advocacy campaign) so students worked in teams on activities that reflected their personal and professional interests. Students who wanted to learn about medical visualizations, for instance, collaborated to create diabetes infographics and other visual communication materials. Students interested in web design tested several web-building platforms (e.g., WordPress, Wix, 
Weebly) to determine which was best suited for the online advocacy campaign. And students interested in digital writing spearheaded the creation of text-based content for the site. In this way, the final project was both useful and usable. Useful in that students could choose activities that served their interests and usable in that students' preferences and needs as learners/users were centralized throughout the development of course projects, an approach that was inclusive of diverse student needs, goals, and desires.

Because most of the students in DeVasto's class were there to fulfill a university requirement, maintaining a focus on usefulness was one strategy for helping them buy into the course. For example, by asking students to self-select a student health issue they were interested in, like depression or nutrition, and analyze how it was communicated about on the University of Wisconsin-Milwaukee campus, their final projects were rooted in rich, authentic contexts that were invested in. When students talked with staff and students on campus, they understood that they were designing for real people. One group, after talking to several students about their health issue, decided to go above and beyond the requirements for primary research by designing a brief survey that they posted to their Class of 2022 Facebook page so that they could get as much input as possible. Despite this not being required and adding to their workload, this strategy was then adopted by several other groups. Finally, by creating and executing an action that engaged some segment of students with their issue, their final projects had the ability to become more than a class requirement to complete; they were meaningful deliverables that responded to and might be used by actual people. This was far more useful for students in the sense that it literally helped them "do better work" and engage more deeply with the work of the course than they might have otherwise. 
In addition to meeting department and university goals, the parameters of their final project also responded to stated student interests in professional training and skills. Modeling the importance and benefit of collaboration between health communicators and communities (Bloom-Pojar \& DeVasto, 2019), students were able to hone critical collaborative skills both within their groups and by working with other campus units (e.g., residence halls, student health center, campus food pantry). Incorporated into this collaborative work were opportunities to practice professional writing skills (e.g., concision, clarity) and workplace genres (e.g., professional email, proposals, memos). Additionally, students were able to get messy and try their hands at the very patient-centered approaches they were reading about in their coursework. By researching the experiences of actual users in the University of Wisconsin-Milwaukee community, students gathered critical insights into local contexts, motivations, preferences, and resources that allowed their work to be more responsive and useful—both to the campus community and for their own careers.

\section{Quality 3: Solicit Input}

$U X$ and patient-centered care recognize that users and patients are not simply recipients. Rather, they have valuable experiences and expertise that should be accounted for. Applying these principles to a classroom setting, a participatory health communication pedagogy solicits student input through consistent feedback loops or checkpoints. In doing so, this pedagogical approach offers a more inclusive classroom space that prioritizes diverse student needs.

In De Hertogh's course, student feedback was consistently solicited through ongoing feedback loops or "checkpoints" where students submitted verbal and written feedback about their learning experiences and provided input on the shape and direction of course projects. For example, students' second project for the course was a team-based report on Type 2 Diabetes in Virginia. To draft the report, the professor, community-partner, and students worked as coauthors to collaboratively determine what the report should include, its layout and format, and 
how to distribute it after completion. Throughout the process of creating the report, student input was solicited in a variety of ways - through small and large group class discussions, team meetings with the professor and community partner, via a shared conversation "channel" in a team-based platform called Slack, and through myriad comments and suggestions on a shared Google doc where students were given full editing permission. Unlike many classroom projects that simply "tack" students onto a pre-existing project, this approach brought in students as real co-authors whose perspectives and contributions were valued and included from the beginning to the end.

Similarly, students in DeVasto's class were regularly invited to check-in during the course of their final project. These check-ins were facilitated by revisiting the organizational documents, like the task schedules and team charters, that each group had created at the outset of their final group project. During these dedicated class times, students reflected on and discussed their progress. For example, students provided input on pacing and deadlines. They identified gaps in their knowledge, like how to create their own data displays, that emerged as their projects progressed and evolved. Space and time was also provided during these check-ins to solicit input on group dynamics. During one check-in, several students shared that they were struggling with the communication channel the group had initially decided upon, which resulted in the group changing their internal communication plan. Another group decided to add a goal to be more intentionally empathetic as the end of the semester approached and stress levels were running high. While these check-ins were primarily done in small groups, this also provided consistent opportunities for groups to check-in with DeVasto and vice versa. These conversations, then, shaped the direction of the group projects and a more usable and supportive learning environment. 


\section{Concluding Thoughts}

What we hope this short article demonstrates is that RHM educators can not only teach about UX and patient-centered care but also use these principles and practices to shape their classrooms. We want to underscore that a participatory health communication pedagogy, built on the principles of UX and patient-centered care, naturally falls into alignment with calls for more socially just pedagogies because this approach focuses on centering the values and voices of students and uplifting their experiences and needs in the classroom.

The case studies introduced in this article begin to illustrate how students can benefit from a participatory health communication pedagogy that decentralizes the instructor's role and prioritizes students as both content creators and content users by merging the guiding frameworks of UX and patient-centered care. This approach certainly requires more time, planning, and effort from educators, and it does, at times, result in "messy" classroom experiences where both teachers and students are learning side-by-side. But ultimately, we see such messiness and co-learning as an advantage because it models the complexities and recursivity of the UX process and patient-centered care and, in doing so, is more responsive to the values and needs of students from a range of backgrounds, languages, and abilities.

Danielle DeVasto is an assistant professor in the Department of Writing at Grand Valley State University. Her research interests reside at the intersections of visual rhetoric, science communication, and uncertainty. Her work has been published in Communication Design Quarterly, Community Literacy Journal, Present Tense, and Social Epistemology.

Lori Beth De Hertogh is an associate professor in the School of Writing, Rhetoric and Technical Communication at James Madison University. Her teaching and scholarship focuses on technical communication, rhetorics health and medicine, and community-engagement. 


\section{References}

Arduser, Lora. (2017). Living chronic: Agency and expertise in the rhetoric of diabetes. Ohio State University Press.

Berry, Leonard L., Beckham, Dan, Dettman, Amy \& Mead, Robert. (2014). Toward a strategy of patient-centered access to primary care. Mayo Clinic Proceedings, 89(10), 1406-1415.

Bloom-Pojar, Rachel \& DeVasto, Danielle. (2019). Visualizing translation spaces for cross-cultural health communication. Present Tense, 7(3), 1-8.

Crane, Kate \& Cargile Cook, Kelli. (2019). User Experience as Innovative Practice. Call for Papers. WAC Clearinghouse/CSU Press.

Hensley Owens, Kim. (2015). Writing childbirth: Women's rhetorical agency in labor and online. Southern Illinois University Press.

James Madison University. Teaching Analysis Polls (TAPs).

Jones, Natasha. (2018). Human centered syllabus design: Positioning our students as expert endusers. Computers and Composition, 25-35.

Kenzie, Daniel \& McCall, Mary. (2018). Teaching writing for the health professions:

Disciplinary intersections and pedagogical practice. Technical Communication Quarterly, 27(1), 64-79.

Malkowski, Jennifer A., J. Blake Scott, \& Lisa Keränen. (2016). Rhetorical approaches to health and medicine. Oxford Research Encyclopedia of Communication, 1-33.

Meloncon Lisa. (2017). Patient experience design: Expanding user experience theory and methods in healthcare contexts. Communication Design Quarterly, 5(2), 19-28.

Mirel, Barbara. (2004). Interaction design for complex problem solving: Developing useful and usable software. Morgan Kaufmann. 
Potts, Liza \& Salvo, Michael J. (2017) Rhetoric and Experience Architecture. Parlor Press.

Scott, J. Blake, Meloncon, Lisa, \& Molloy, Cathryn. (2020). RHM's Response to Racial Injustice. http://medicalrhetoric.com/rhms-racial-injustice-response/

Shivers-McNair, Ann, Phillips, Joy, Campbell, Alyse, Mai, Hanh H., Yan, Alice, Macy, John Forest, Wenlock, James, Fry, Savannah \& Guan, Yishan. (2018). User-centered design in and beyond the classroom: Toward an accountable practice. Computers and Composition, 49, 36-47.

Simmons, W. Michelle \& Zoetewey, Meredith W. (2012). Productive usability: Fostering civic engagement and creating more useful online spaces for public deliberation. Technical Communication Quarterly, 21(3), 251-276.

Singer, Sarah Ann. (2019). Health information sharing as feminist rhetorical work: Rethinking power, individuality, and simplicity in Women and Their Bodies. Peitho, 21(3), 655-675.

Stone, Mary Specker. (1997). In search of patient agency in the rhetoric of diabetes care. $T C Q$, 6(2), 201-217.

Usability.gov. (n.d.) "User Experience Basics." https://www.usability.gov/what-and-why/user-experience.html 